\title{
Potentiometric Determination of Prednisolone in Pharmaceutical Formulations
}

\author{
Gehan A. Zaki ${ }^{1, *}$, Mohamed E.M. Hassouna ${ }^{2}$ \\ ${ }^{1}$ Faculty of Arts and Sciences, Northern Border University, Rafha, Saudi Arabia. \\ ${ }^{2}$ Chemistry Department, Faculty of Science, Beni-Suef University, Egypt.
}

\section{A R T I C LEDE T A I L S}

\section{Article history:}

Received 24 June 2021

Accepted 04 July 2021

Available online 28 September 2021

\section{Keywords:}

Prednisolone

Pharmaceutical Preparations

PVC Membrane Electrode

\section{A B S T R A C T}

In this present work, a prednisolone ion selective electrode (PRED-ISE) has been developed. The electrode shows linear response towards prednisolone in the range $3.0 \times 10^{-6}-8.6 \times 10^{-3} \mathrm{M}$ with a detection limit of $2.5 \times 10^{-6}$. PRED-ISE was used as an indicator electrode for the potentiometric titration of different concentrations of standard prednisolone against standardized sodium tetraphenyl borate solution and in tablets. The electrode manifests advantages of low resistance, fast response and, most importantly, good selective relativity to a variety of other cations.

\section{Introduction}

Prednisolone is a synthetic steroid that is chemically defined as $11 \beta, 17 \alpha, 21$-trihydroxypregna-1,4-diene-3,20-dione (Fig. 1). Prednisolone is a glucocorticoid that is extensively used in clinical practice. Its therapeutic use is recommended for a variety of acute and chronic diseases, such as arthritis, allergic diseases, asthma, leprosy, and numerous other autoimmune and inflammatory diseases. Several methods based on liquid chromatography with UV detection have been reported [1-12], for the determination of prednisolone in plasma and some voltammetric methods have been developed [13-16]. Thus, the present method aimed at advocating of a new PRED-ISE as simple and accurate tool for the determination of prednisolone in authentic solutions, tablets and in spiked urine samples.<smiles>C[C@@]12C=CC(=O)C=C1CC[C@@H]1[C@@H]2[C@@H](O)C[C@@]2(C)[C@H]1CC[C@]2(O)C(=O)CO</smiles>

Fig. 1 Structure of prednisolone $\mathrm{C}_{21} \mathrm{H}_{28} \mathrm{O}_{5}$, Molecular weight: 360.4

\section{Experimental Methods}

\subsection{Reagents and Materials}

All reagents were of analytical grade. Prednisolone (PRED) (99.97\%) was procured from Drug Research Organization (DRO, Egypt). High relative molecular weight poly(vinyl chloride) (PVC), and tetrahydrofuran (THF) from Aldrich and Ortho-nitrophenyloctylether (O-NPOE) from Fluka, dibutylphthalate (DBP) from Riedel de Hein, sodium tetraphenylborate (NaTPB) from Panreac were purchased for the present study. Predilone ( $5 \mathrm{mg}$ ) tablets collected for application study which was produced by Kahira Pharm \& Chem. Ind. Co. Cairo, Egypt. Since PRED is very slightly soluble in water [17] (1 g dissolves in 1000-10,000 mL), stock PRED solution $(0.01 \mathrm{M})$ was prepared by adding few drops of $2 \mathrm{M} \mathrm{HCl}$ to a stirred aqueous suspension containing 0.3604 g PRED till complete dissolution of the solid and made up to $100 \mathrm{~mL}$ with distilled water.

\subsection{Preparation of PRED-TPB Ion Pair}

PRED - TPB ion pair was prepared by mixing $25 \mathrm{~mL}$ of each of $0.01 \mathrm{M}$ PRED solution and NaTPB with stirring. The white precipitate that formed was filtered, washed with distilled water, dried and finely powdered.

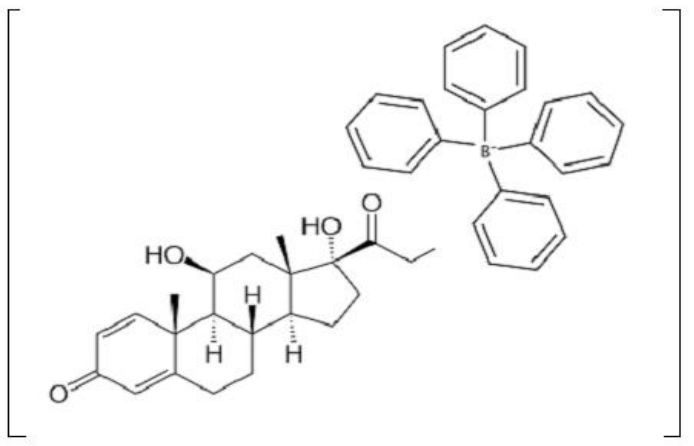

Fig. 2 Chemical structure of PRED-TPB ion pair

Fig. 2 shows the proposed structure of the formed ion pair in the ratio of $1: 1$ with the molecular formula of $\left(\left[\mathrm{C}_{21} \mathrm{H}_{27} \mathrm{O}_{4}\right]\left[\mathrm{C}_{24} \mathrm{H}_{20} \mathrm{~B}\right]\right)$ ion pair $=663$ $\mathrm{g} / \mathrm{mol}$, which was concordant with the $\mathrm{C} \& \mathrm{H}$ percentages in the elemental analysis report that was carried out at Micro Analytical center, Cairo University, Egypt (Table 1).

Table 1 Elemental analysis of PRED-TPB $\left(\left[\mathrm{C}_{21} \mathrm{H}_{27} \mathrm{O}_{4}\right]\left[\mathrm{C}_{24} \mathrm{H}_{20} \mathrm{~B}\right]\right)$ ion pair

\begin{tabular}{lll}
\hline Element & $\% \mathrm{C}$ & $\% \mathrm{H}$ \\
\hline Calculated & 81.4 & 7.09 \\
Found & 81.3 & 7.08 \\
\hline
\end{tabular}

\subsection{Preparation of Membrane}

Table 2 shows the influence of the membrane composition on the characteristics of the electrodes. Each composition was mixed and dissolved in $2 \mathrm{~mL}$ THF, the resulting solution was poured into $2.5 \mathrm{~cm}$ diameter glass ring placed on petri dish. After slow evaporation of THF at room temperature for $36 \mathrm{~h}$, membranes with $\sim 0.2 \mathrm{~mm}$ thickness were formed. These membranes were used for electrode construction. 
Table 2 Influence of the membrane composition on the characteristics of the electrodes

\begin{tabular}{|c|c|c|c|c|c|c|c|c|}
\hline Electrode No. & PRED-TPB (mg) & PVC (mg) & Plasticizer & Slope mV/decade & Regression Coefficient & Linear range (M) & LOD (M) & Response time (s) \\
\hline 1 & 2 & 60 & DBP (120) & 54.9 & 0.997 & $10^{-4}-10^{-2}$ & $1 \times 10^{-5}$ & 10 \\
\hline 2 & 3 & 60 & DBP (120) & 55.6 & 0.999 & $10^{-5-10^{-2}}$ & $8.5 \times 10^{-6}$ & 8 \\
\hline 3 & 4 & 60 & DBP (120) & 56.7 & 0.998 & $10-5-10^{-2}$ & $2.1 \times 10^{-6}$ & 6 \\
\hline 4 & 3 & 60 & ONPOE (120) & 55.8 & 0.998 & $10^{-5}-10^{-2}$ & $3.4 \times 10^{-6}$ & 5 \\
\hline 5 & 4 & 60 & ONPOE (120) & 59.1 & 0.999 & $10^{-5}-10^{-2}$ & $3.2 \times 10^{-6}$ & 5 \\
\hline
\end{tabular}

\subsection{Electrode Construction}

Electrodes were assembled by cutting 6-mm diameter disks from the prepared membranes and mounting them into the polished end of PVC tubing (4-mm i.d.) using 5\% PVC-THF solution. The electrodes were then filled with a $10^{-4} \mathrm{M}$ PRED as the internal filling solution and were conditioned in a solution of the same composition.

\subsection{Electrochemical System}

Potentiometric measurements were performed using a Jenway 3010 digital $\mathrm{pH} / \mathrm{mV}$ meter (Stone, Staffordshire, UK). Packed saturated calomel electrode (SCE) was used as an external reference electrode.

\subsection{Selectivity of Electrode}

The selectivity coefficients $\log K_{P R E D, I}^{P O t}$ were determined by the separate solutions method (SSM) in which the potential of a cell, comprising PREDISE and $\mathrm{Ag} / \mathrm{AgCl}$ reference electrode was measured with each of the two separate solutions: the first is $1 \times 10^{-4} \mathrm{M}$ PRED, and the other is $1 \times 10^{-4} \mathrm{M}$ interferent I. The value of $\log K_{P R E D, I}^{P o t}$ was calculated from equation:

$$
\log K_{P R E D, I}^{P o t}=\left(\frac{\left(E_{2}-E_{1}\right.}{s}\right)+\left(1-\left(\frac{z_{P R E D}}{z_{s}}\right)\right) \log \left[1 \times 10^{-4}\right]
$$

where $E_{1}$ and $E_{2}$ are the measured EMF values for the two solutions, respectively, and $\mathrm{S}$ is the slope of the calibration graph [18]. The selectivity coefficients in case of neutral and organic species were determined by the matched potential method (MPM). In this method, the potentiometric selectivity coefficient is defined as the activity ratio of primary and interfering ions that gives the same potential change under identical conditions. A known activity $\left(a_{\mathrm{A}}\right.$ ) $)$ of PRED solution is added into a reference solution that contains a fixed activity $\left(\mathrm{a}_{A} ; 1 \times 10^{-5} \mathrm{M}\right)$ of PRED, and the corresponding potential change $(\Delta \mathrm{E})$ is recorded. Next, a solution of an interfering ion is added to the reference solution until the same potential change $(\Delta E)$ is recorded. The change in potential produced at the constant background of the primary ion must be the same in both cases [19]. The selectivity factor for $K_{P R E D}^{M P M}$, each interferent was calculated using the equation:

$$
K_{P R E D}^{M P M}=\frac{\left(a_{A}^{\prime}-a_{A}\right)}{a_{I}}
$$

Pharmaceutical dosage forms may be associated with flavoring agents, diluents and excipients, such as maltose, sucrose, glucose, lactose, starch, and magnesium stearate. So, the response of the electrode to different substances has been investigated and the selectivity coefficient was used to evaluate the degree of interference.

The selectivity coefficients shown in Table 3 reveal the high selectivity of the proposed electrode towards PRED ion. The inorganic cations did not interfere due to the differences in their mobility and permeability, compared to PRED. In case of sugars and amino acids, the high selectivity is mainly attributed to the difference in polarity and to the moderately hydrophobic nature of their molecules relative to PRED.

\subsection{Potentiometric Determination of PRED}

\subsubsection{Direct Calibration Method}

PRED-ISE was used as an indicator electrode for the potentiometric titration of PRED in pure solution and in tablets. $25 \mathrm{~mL}$ aliquots of PRED standards; $1 \times 10^{-4} \mathrm{M}, 10^{-3} \mathrm{M}$, were titrated against $0.01 \mathrm{M}$ NaTPB solution. Predilone $(5 \mathrm{mg})$ tablets were suspended in water under stirring with addition of few drops of $2 \mathrm{M} \mathrm{HCl}$. The volumes of titrant at the end points were obtained using the differential method. Tablets were suspended in water then few drops of $2 \mathrm{M} \mathrm{HCl}$ were added, and the solutions were diluted to $25 \mathrm{~mL}$ with water, the EMF were recorded and the PRED concentration was calculated from the corresponding calibration curves.

\subsubsection{Standard Addition Method}

In the standard addition method, small increments $(0.25-1.5 \mathrm{~mL})$ of $0.010 \mathrm{M}$ standard PRED solution were added to the previous solutions https://doi.org/10.30799/jacs.240.21070302
[20]. The change in millivolt readings at constant temperature of $25 \pm 1{ }^{\circ} \mathrm{C}$ was recorded for each increment and used to calculate the concentration of PRED sample solutions using the equation:

$$
C_{x}=\left(\frac{C_{s t} V_{s t}}{V x}\right)\left(\frac{1}{\left(10^{\Delta E} / s\right)-1}\right)
$$

where $C_{x}$ is the concentration of PRED in the test sample, $C_{s t}$ is the concentration of the standard solution, $V_{x}$ and $V_{s}$ are the corresponding volumes, $\mathrm{S}$ is the slope of the calibration curve, and $\Delta \mathrm{E}$ is the change in millivolts due to the addition of standard solution.

Table 3 Potentiometric selectivity coefficients for the PRED-ISE

\begin{tabular}{llll}
\hline Interferent & $-\log K_{\text {PRED, A }}$ & Interferent & $-\log K_{\text {PRED , B }}$ \\
\hline $\mathrm{NH}_{4}{ }^{+}$ & 4.0 & Glucose & 5.3 \\
$\mathrm{~K}^{+}$ & 3.0 & Fructose & 5.1 \\
$\mathrm{Na}^{+}$ & 2.9 & Maltose & 5.0 \\
$\mathrm{Li}^{+}$ & 3.3 & Alanine & 4.7 \\
$\mathrm{Mg}^{2+}$ & 3.0 & Citric acid & 4.7 \\
$\mathrm{Cu}^{2+}$ & 3.3 & Urea & 4.9 \\
$\mathrm{Cd}^{2+}$ & 3.1 & Lactose & 5.0 \\
$\mathrm{Ca}^{2+}$ & 3.4 & Ascorbic acid & 5.2 \\
$\mathrm{Mn}^{2+}$ & 3.3 & Glycine & 4.9 \\
$\mathrm{Ni}^{2+}$ & 3.4 & Starch & 5.0 \\
$\mathrm{Al}^{3+}$ & 4.2 & & \\
\hline $\mathrm{A}, \mathrm{B}$ & &
\end{tabular}
one (MPM)

\section{Results and Discussion}

\subsection{Optimization of Membrane Composition}

The data shown in Table 1 clearly indicates that 4 mg of PRED -TPB-ion pair is enough to obtain near Nernstian response, good sensitivity and wide working range. Membranes plasticized with $O$-NPOE gave a slightly better detection limit compared with DBP, so $O$-NPOE was chosen for subsequent investigations.

\subsection{Effect of $p H$}

The influence of the $\mathrm{pH}$ of a test solution on the proposed PRED electrode potentiometric response was studied at three PRED concentrations $\left(1 \times 10^{-4}, 1 \times 10^{-3}\right.$ and $\left.1 \times 10^{-2} \mathrm{M}\right)$ where the $\mathrm{pH}$ was adjusted from 1 to 10 with $\mathrm{HCl}$ and/or $\mathrm{NaOH}(0.1-1.0 \mathrm{M})$. The observed results are presented in Fig. 3. As it can be seen, the potential is independent on the $\mathrm{pH}$ changes in the range of $4-8$. Thus, this range was chosen as the working $\mathrm{pH}$ for the electrode assembly [21]. At $\mathrm{pH}<4$, the PRED anion was protonated, whereas, at relatively high $\mathrm{pH}>8$ the potential decreases more significantly probably due to membrane response to $\mathrm{OH}^{-}$[22].

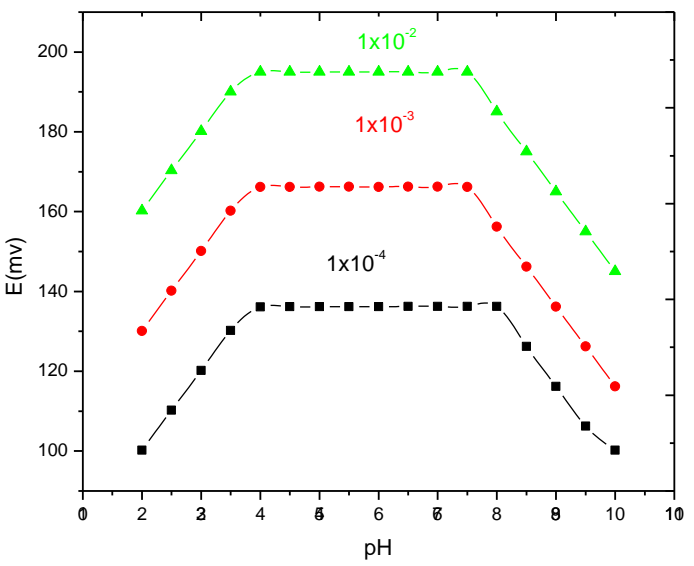

Fig. 3 Effect of $\mathrm{pH}$ of the test solution on the potential response of PRED-TPBelectrode 


\subsection{Effect of Temperature}

To study the thermal stability of the electrodes, calibration graphs were constructed at different test solutions with temperatures varying in the range $\left(25-70{ }^{\circ} \mathrm{C}\right)$, and the isothermal coefficients $(\mathrm{dE} / \mathrm{dt})$ of the selected electrodes were calculated [23]. For the determination of the isothermal coefficients $\left(d E^{\circ} / \mathrm{dt}\right)$ of the cell, the standard electrode potentials $E^{\circ}$, obtained from the calibration graphs as the intercepts at $P^{P R E D}=0$ were plotted versus (t-25) as shown in Figs. 4 and 5 where $t$ is the temperature $\left({ }^{\circ} \mathrm{C}\right)$ of the test solution. A straight-line plot was obtained according to the equation: $\mathrm{E}^{\circ}=0.35(\mathrm{t}-25)+381.9$. The value indicates good thermal stability of the electrodes.

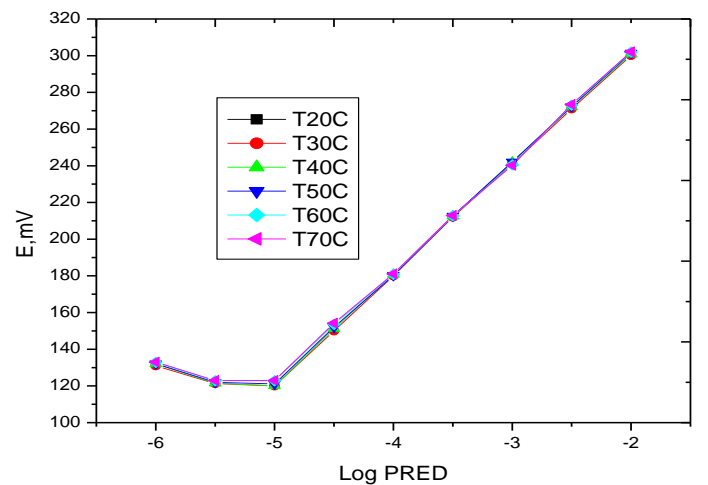

Fig. 4 Calibration graphs for the proposed electrode at varied temperatures

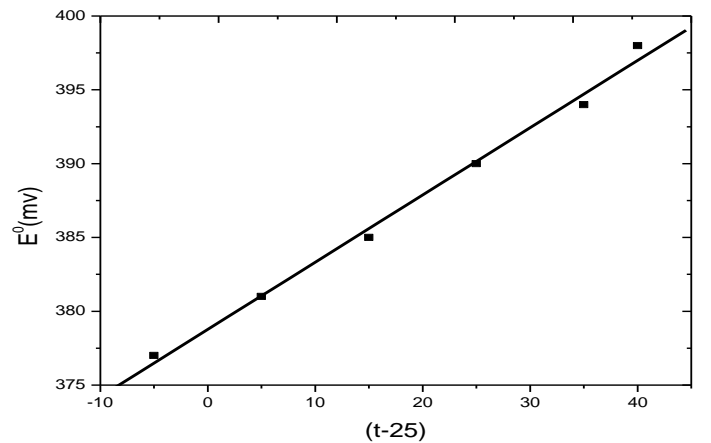

Fig. 5 Variation of $\mathrm{E}^{\circ}$ (Cell) of the proposed PRED -TPB- electrode with temperature

\subsection{Effect of Internal Filling Solution}

The effect of internal filling solution composition was investigated using different solutions of pure PRED $\left(10^{-5}\right.$ to $\left.10^{-3} \mathrm{M}\right)$ (Fig. 6). The obtained results showed that the variation of the internal solution composition did not produce any significant difference in the potential response. Therefore $10^{-3} \mathrm{M}$ PRED was chosen as the internal solution composition in the subsequent studies [24].

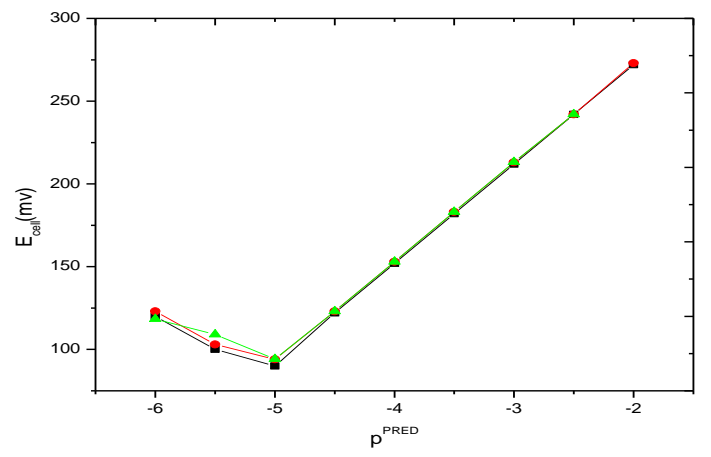

Fig. 6 Effect of internal solution composition on the electrode response

\subsection{Response Time of the Electrode}

Dynamic response time is a factor of considerable value for any sensor in the field of analytical applications. The average time that was required for the PRED sensor to reach a potential within $\pm 1 \mathrm{mv}$ of the final equilibrium value was measured. In this study, the practical response time has been recorded by changing the different PRED concentrations solutions $\left(1 \times 10^{-6}-1 \times 10^{-2} \mathrm{M}\right.$ PRED). After each measurement, the solution was rapidly changed. Such a change required nearly 5-8 $\mathrm{s}$. The actual potential versus time curve is shown in Fig. 7, here the electrode reached the equilibrium response in a very short time of about $8 \mathrm{~s}$. https://doi.org/10.30799/jacs.240.21070302

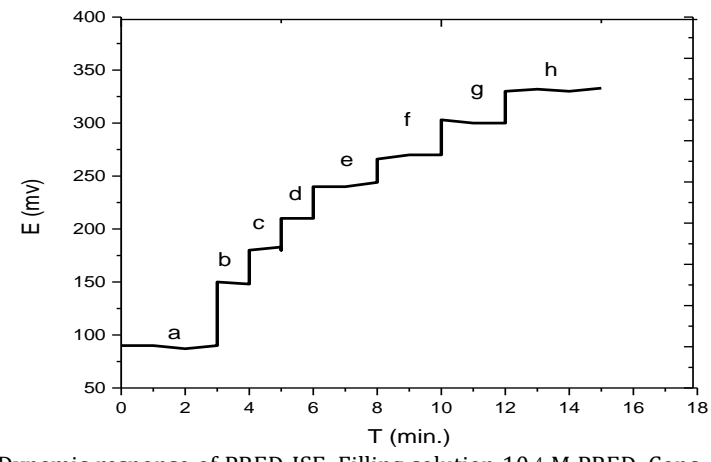

Fig. 7 Dynamic response of PRED-ISE. Filling solution $10^{-4}$ M PRED. Conc.: (a) $10^{-6}$, (b) $10^{-5}$, (c) $5 \times 10^{-5}$, (d) $10^{-4}$, (e) $5 \times 10^{-4}$, (f) $10^{-3}$, (g) $5 \times 10^{-3}$ and (h) $10^{-2} \mathrm{M}$

\subsection{Life Time of the Ion Selective Electrode}

The electrode lifetime was investigated by performing the calibration curve and the periodical testing of standard solutions $\left(1 \times 10^{-6}-1 \times 10^{-2} \mathrm{M}\right.$ PRED) and calculating the response slopes. It was observed that the proposed electrodes exhibited good stabilities in terms of slope in the linear domain of concentration and the electrodes can be used continually for about 1.5 months without considerable decrease in its slope value [25].

\subsection{Analytical Applications and Statistical Evaluation of Results}

The investigated electrodes were proved to be useful in the potentiometric determination of PRED both in pure solutions and in pharmaceutical preparations. For predilone $(5 \mathrm{mg})$ and prednisolone solution ( $100 \mu \mathrm{g} / \mathrm{mL}$ in acetonitrile, $1 \mathrm{~mL}$ ampule), the mean recovery and relative standard deviation values are summarized in Table 4 . The data indicate that there is no interference from the excipients used in the formulations of the tablets or ampules.

The results showed that the calculated $t$ - and $F$-values did not exceed the theoretical values which mean that there is no difference between the present method and the references in terms of accuracy and precision. The electrodes were utilized as indicator electrodes in the potentiometric titration of different concentrations of PRED standards against standardized NaTPB solution. Typical titration curves with sharp inflection breaks were obtained as shown in Fig. 8.

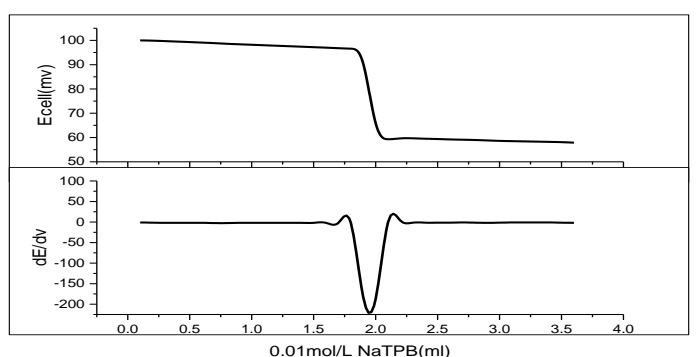

Fig. 8 Titration of $20 \mathrm{~mL}$ of $1 \times 10^{-3} \mathrm{M}$ PRED with $0.01 \mathrm{M}$ NaTPB using PRED-ISE

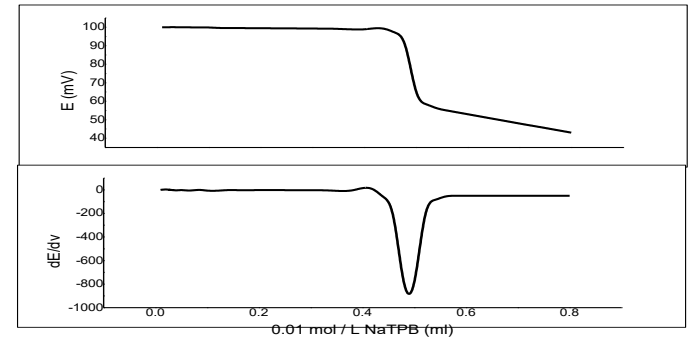

Fig. 9 Potentiometric titration of dissolved predilone tablets vs. 0.001 M NaTPB

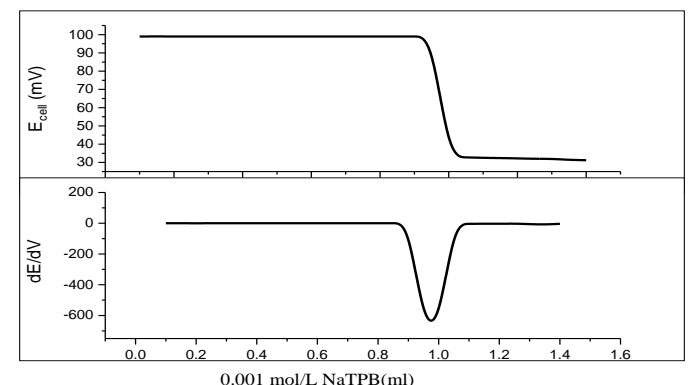

Fig. 10 Potentiometric titration of prednisolone solution $(100 \mu \mathrm{g} / \mathrm{mL}) 1 \mathrm{~mL}$ ampule 
Table 4 Determination of PRED in pharmaceutical preparations

\begin{tabular}{|c|c|c|c|c|c|c|c|c|c|c|c|c|}
\hline \multirow{2}{*}{$\frac{\text { Method }}{\text { Batch technique }}$} & \multicolumn{6}{|c|}{ Predilone ( $5 \mathrm{mg}$ per tablet) } & \multicolumn{6}{|c|}{ Prednisolone solution ( $0.1 \mathrm{mg} / \mathrm{L})$ ampule of $1 \mathrm{~mL}$} \\
\hline & Found & Recovery $\%$ & SD & $\%$ RSD & aF-Test & bt- Test & Found & Recovery $\%$ & SD & $\%$ RSD & aF-Test & bt- Test \\
\hline Direct calibration & 4.9 & 98.0 & 0.03 & 1 & 7.2 & 5.4 & 0.097 & 97 & 0.029 & 0.9 & 7.1 & 5.3 \\
\hline Standard additions & 4.9 & 98.0 & 0.03 & 1 & 3.4 & 5.6 & 0.099 & 99 & 0.025 & 0.7 & 3.5 & 5.4 \\
\hline Potentiometric titration & 4.8 & 96.0 & 0.038 & 0.7 & 9.0 & 5.0 & 0.098 & 98 & 0.027 & 0.8 & 9.2 & 5.1 \\
\hline HPLC Method [26] & 5.1 & 103.3 & 0.01 & 0.2 & & & 0.102 & 102 & 0.03 & 1.0 & & \\
\hline
\end{tabular}

The application of the potentiometric titration was successful in predilone samples and prednisolone solution. Highly reproducible titration curves were obtained with very sharp inflection breaks as shown in Figs. 9 and 10. As shown in Table 4, good agreement found between the recoveries obtained by the proposed and the modified HPLC method. Statistical evaluation of the results showed that there is no significant difference between the proposed and reference methods in terms of accuracy and precision.

\subsubsection{Determination of Predilone in Spiked Urine Samples}

Urine samples of healthy volunteers who had not taken any medicine at least one preceding week were deproteinized with methanol. To an aliquot (1 $\mathrm{mL}$ ) of the deproteinized urine sample standard PRED solution was added within the calibration range and processed as the recommended analytical procedure.

The found amount agreed with the spiked values with RSD \% of the replicate analysis $(\mathrm{n}=3)$ were within $0.6-1 \%$ and calculated recoveries of $98.3-103 \%$ and $97-98.3 \%$ for the standard addition and the potentiometric titration methods, respectively. The mean recoveries and relative standard deviations were calculated and summarized in Table 5. Good recoveries were obtained for both systems.

Table 5 Determination of predilone in spiked urine samples by applying standard addition and potentiometric titration method

\begin{tabular}{llll}
\hline Standard addition method & Taken (mol/L) & Recovery (\%) & R.S.D. (\%) \\
\cline { 2 - 4 } & $1 \times 10^{-4}$ & 98.7 & 1.0 \\
& $5 \times 10^{-3}$ & 98.3 & 0.8 \\
& $5 \times 10^{-4}$ & 103 & 0.8 \\
\hline Potentiometric titration & $2.5 \times 10^{-4}$ & 98.1 & 0.4 \\
method & $5 \times 10^{-4}$ & 97.9 & 0.9 \\
& $1 \times 10^{-3}$ & 97 & 0.6 \\
\hline
\end{tabular}

The comparisons between our proposed electrode and previously published methods are shown in Table 6. The new electrode shows high linearity range and the little response time and short time of analysis. ElRageh, et al. [16] have reported the potentiometric determination of sulfacetamide $\mathrm{Na}$ in presence of prednisolone, with the comparison of their response time. It is clear that their proposed electrode is faster and having longer lifetime of 6 weeks [16].

Table 6 Comparison of the PRED-ISE and some previous works

\begin{tabular}{|c|c|c|c|c|}
\hline Methods & linearity range & $\begin{array}{l}\text { Analysis } \\
\text { time }\end{array}$ & Applications & Ref. \\
\hline Proposed & $3.0 \times 10^{-6}-$ & $5.00-$ & Pharmaceutical formulations & \\
\hline Electrode & $8.6 \times 10^{-3} \mathrm{M}$ & $8.00 \mathrm{~S}$ & and spiked human urine & \\
\hline HPLC & $40-160 \mu \mathrm{gmL}^{-1}$ & $7.50 \mathrm{~min}$ & Pharmaceutical formulations & {$[27]$} \\
\hline HPLC & & $12.00 \mathrm{~min}$ & Cochlear tissue & [1] \\
\hline HPLC-MS/MS & $5-250 \mu \mathrm{gL}^{-1}$ & $5.54 \mathrm{~min}$ & Cosmetics samples & {$[28]$} \\
\hline $\mathrm{GC} / \mathrm{Ms}$ & $10-500 \mathrm{ng} / \mathrm{mL}$ & $5.00 \mathrm{~min}$ & Human plasma & {$[6]$} \\
\hline HPLC & $25-400 \mathrm{ng} / \mathrm{mL}$ & $8.00 \mathrm{~min}$ & Human plasma & [29] \\
\hline MEKC & $0.8-56.5 \mathrm{mg} / \mathrm{L}$ & $6.00 \mathrm{~min}$ & Pharmaceutical preparations & {$[30]$} \\
\hline LC/MS/MS & $4.80-400 \mathrm{ug} / \mathrm{mL}$ & $3.82 \mathrm{~min}$ & Human plasma & [31] \\
\hline $\begin{array}{l}\text { Reversed } \\
\text { phase HPLC }\end{array}$ & $2-1000 \mathrm{ng} / \mathrm{mL}$ & $19.90 \mathrm{~min}$ & Human plasma & {$[4]$} \\
\hline SWV & $0.06-40 \mu \mathrm{M}$ & & $\begin{array}{l}\text { Pharmaceutical formulations } \\
\text { and spiked human urine }\end{array}$ & {$[32]$} \\
\hline Voltammetry & $\begin{array}{l}0.45 \times 10^{-8}- \\
0.90 \times 10^{-8} \mathrm{~mol} / \mathrm{L}\end{array}$ & & $\begin{array}{l}\text { Human body fluids and } \\
\text { pharmaceutical preparations }\end{array}$ & [33] \\
\hline Voltammetry & $10-500 \mathrm{ug} / \mathrm{mL}$ & & $\begin{array}{l}\text { Adulterated traditional } \\
\text { medicines }\end{array}$ & [13] \\
\hline potentiometry & $\begin{array}{l}1 \times 10^{-4.5}-1 \times \\
10^{-2} \mathrm{M}\end{array}$ & $\begin{array}{l}10.00- \\
15.00 \mathrm{~s}\end{array}$ & $\begin{array}{l}\text { Application to its } \\
\text { pharmaceutical formulations } \\
\text { and spiked rabbit aqueous } \\
\text { humor }\end{array}$ & [16] \\
\hline
\end{tabular}

\section{Conclusion}

By the in-depth review of existing procedures for the determination of PRED which require special instrumentation and prior separation, the Compared with the already existing procedures for the determination of PRED which require special instrumentation and prior separation, the proposed PVC membrane electrodes method based on PRED-TPB-ion pair exhibits the advantages of fast response, reasonable selectively and sufficient accuracy. The proposed electrode was successfully used for the determination of PRED in pure form, pharmaceutical formulations and in spiked urine samples. The present PRED-TPB- ion pair exhibits the advantages of low cost, simple design and operation, fast response, reasonable selectively and sufficient accuracy. The proposed electrode was successfully used for the determination of PRED in pure form, pharmaceutical formulations and in spiked urine samples.

\section{Acknowledgments}

The authors acknowledge Chemistry Department, Faculty of Arts and Sciences, Northern Border University, Rafha, Saudi Arabia for providing facilities during the performance of this work.

\section{References}

[1] M. Rohitas, A. Agrawal, A.K. Jain, N.K. Lariya, A.K. Kharya, G.P. Agrawal, Development of simultaneous spectrophotomertic method of mesalazine and prednisolone in same dosage form, Int. J. Appl. Pharm. 2 (2010) 8-11.

[2] A.F.C. Ruiter, N. Teeninga, J. Nauta, E. Endert, M.T. Ackermans, Determination of unbound prednisolone, prednisone and cortisol in human serum and saliva by on-line solid-phase extraction liquid chromatography tandem mass spectrometry and potential implications for drug monitoring of prednisolone and prednisone in saliva, Biomed. Chromatogr. 26 (2012) 789-796.

[3] T. Ui, M. Mitsunaga, T. Tanaka, M. Horiguchi, Determination of prednisone and prednisolone in human serum by high-performance liquid chromatographyespecially on impaired conversion of corticosteroids in patients with chronic liver disease, J. Chromatogr. 239 (1982) 711-716.

[4] C.Y. Cho, B. Shin, S.D. Yoo, Sensitive Analysis of prednisolone and prednisone in human plasma by reverse phase high-performance liquid chromatography with ultraviolet detection, J. Anal. Lett. 36 (2003) 1573-1585.

[5] V. Giaccone, G. Polizzotto, A. Macaluso, G. Cammilleri, V. Ferrantelli, Determination of ten corticosteroids in illegal cosmetic products by a simple, rapid, and high-performance LC-MS/MS method, Int. J. Anal. Chem. 75 (2017) $1-12$.

[6] H. Shibasaki, H. Nakayama, T. Furuta, Y. Kasuya, M. Tsuchiya, et al., Simultaneous determination of prednisolone, prednisone, cortisol, and cortisone in plasma by GC-MS: Estimating unbound prednisolone concentration in patients with nephrotic syndrome during oral prednisolone therapy, J. Chromato. B 870 (2008) 164-169.

[7] J.M.L. Gallego, J.P. Arroyo, Determination of prednisolone, naphazoline, and phenylephrine in local pharmaceutical preparations by micellar electrokinetic chromatography, J. Sep. Sci. 26 (2003) 947-952.

[8] A.N.B. Fonte, M.P. Legró, Y.R. Céspedes, Simple and fast RP-HPLC method for the determination of prednisolone sodium phosphate, prednisolone, atropine, and homatropine as residuals in cleaning validation of industrial pharmaceutical equipment, J. Liquid Chromato. Related Tech. 36 (2013) 213228.

[9] R.A. Sversut, M.S. Amaral, A.C.M. Baroni, P.O. Rodrigues, A.M. Rosa, et al. Stability-indicating HPLC-DAD method for the simultaneous determination of fluoroquinolones and corticosteroids in ophthalmic formulations, Anal. Methods 6 (2014) 2125-2133.

[10] T. Tobita, M. Senarita, A. Hara, J. Kusakari, Determination of prednisolone in the cochlear tissue, Hearing Res. 165 (2002) 30-34.

[11] X. Ding, M.J. Rose, I.M. Caffery, J. Rossi, K. Pageletm, et al., Determination of prednisolone in human adipose tissue incubation medium using LC-MS/MS to support the measurement of $11 \beta$-hydroxysteroid dehydrogenase activity, J. Chromatogr. B 877 (2009) 1394-1401.

[12] M. Finšgar, A. Perva-Uzunalić, H. Behr, N. Ledinek, Ž. Knez, Z. Novak, An improved reversed-phase high-performance liquid chromatography method for the analysis of related substances of prednisolone in active ingredient, ACS Omega 14 (2020) 7987-8000.

[13] V. Primpray, O. Chailapakul, M. Tokeshi, T. Rojanarata, W. Laiwattanapaisal, A paper-based analytical device coupled with electrochemical detection for the determination of dexamethasone and prednisolone in adulterated traditional medicines, Anal. Chim. Acta 1078 (2019) 16-23. 
[14] A.A. Al-rashdi, O.A. Farghaly, A.H. Naggar, Voltammetric determination of pharmaceutical compounds at bare and modified solid electrodes, J. Chem. Pharma. Res. 10 (2018) 21-43.

[15] R.N. Goyal, S. Bishnoi, Simultaneous voltammetric determination of prednisone and prednisolone in human body fluids, Talanta 79 (2009) 768-774.

[16] N.A. El-Ragehy, M.A. Hegazy, G. Abd. El Hamid, S.A. Tawfik, Validated potentiometric method for the determination of sulfacetamide sodium; application to its pharmaceutical formulations and spiked rabbit aqueous humor, J. Bull. Faculty Pharm. Cairo Univ. 56 (2018) 207-212.

[17] M. Vogt, J. Krämer, H.E. Junginger, K.K. Midha, V.P. Shah, et al., Biowaiver monographs for immediate release solid oral dosage forms: Prednisolone, J. Pharm. Sci. 96 (2007) 1480-1489.

[18] Y. Umezawa, P. Bühlmann, K. Umezawa, K. Tohda, S. Amemiya, Potentiometric selectivity coefficients of ion-selective electrodes Part I. Inorganic cations (technical report), Pure Appl. Chem. 72 (2000) 1851-2082.

[19] K.Y. Chumbimuni-Torres, N. Rubinova, A. Radu, L.T. Kubota, E. Bakker, Potentiometric sensors for trace-level analysis, Anal. Chem. 78 (2006) 13181322.

[20] E. Khaled, H.N.A. Hassan, A. Girgis, R. Metelka, Construction of novel simple phosphate screen-printed and carbon paste ion-selective electrodes, Talanta 77 (2008) 737-743.

[21] Y.M. Issa, S.I.M. Zayed, Flow injection potentiometric determination of clobutinol hydrochloride, Talanta 69 (2006) 481-487.

[22] M. Arvand, S.A. Asadollahzadeh, Ion-selective electrode for aluminum determination in pharmaceutical substances, tea leaves and water samples, Talanta 75 (2008) 1046-1054.

[23] T.A. Ali, G.G. Mohamed, Modified screen-printed ion selective electrodes for potentiometric determination of sodium dodecylsulfate in different samples, J. AOAC Inter. 98 (2015) 116-123.
[24] R.S. Staden, A.A. Ratko, Enantioselective, potentiometric membrane electrodes based on cyclodextrins: Application for the determination of R-baclofen in its pharmaceutical formulation, Talanta 69 (2006) 1049-1053.

[25] S.M. Marxer, M.H. Schoenfisch, Sol-gel derived potentiometric pH sensors, Anal. Bioanal. Chem. 77 (2005) 838-853.

[26] P.A. Williams, E.R. Biehl, High-Pressure liquid chromatographic determination of corticosteroids in topical pharmaceuticals, J. Pharm. Sci. 70 (1981) 530-534

[27] S.N. Razzaq, I.U. Khan, I. Mariam, S.S. Razzaq, Stability indicating HPLC method for the simultaneous determination of moxifloxacin and prednisolone in pharmaceutical formulations, Chem. Cent. J. 94 (2012) 7-10.

[28] V. Giaccone, G. Polizzotto, A. Macaluso, G. Cammilleri, V. Ferrantelli, Determination of ten corticosteroids in illegal cosmetic products by a simple, rapid, and high-performance LC-MS/MS method, Int. J. Anal. Chem. 2 (2017) 112.

[29] A.P. Scott, V.J. Bye, S.M. Baynes, Seasonal variations in sex steroids of female rainbow trout (Salmo gairdneri Richardson), J. Fish Biol. 17 (1980) 587-592.

[30] J.M.L. Gallego, J.P. Arroyo, Determination of prednisolone, naphazoline, and phenylephrine in local pharmaceutical preparations by micellar electrokinetic chromatography, J. Sep. Sci. 26 (2003) 947-952.

[31] D. Robin, V. Frerichs, J. Donnelly, C. Hagler, J. Hochreiter, K.M. Tornatore, Simultaneous determination of cortisol, dexamethasone, methylprednisolone, prednisone, prednisolone, mycophenolic acid and mycophenolic acid glucuronide in human plasma utilizing liquid chromatography mass spectrometry, J. Chromatogr. B Anal. Technol. Biomed. Life Sci. 859 (2007) 42 51.

[32] A. Munyentwali, Electrochemical determination of prednisolone at ordered mesoporous carbon modified electrode: Application to doping monitoring, J. Electro. Soc. 162 (2015) 278-282.

[33] R.N. Goyal, S. Bishnoi, Simultaneous voltammetric determination of prednisone and prednisolone in human body fluids, Talanta 79 (2007) 768-774. 